\title{
Os diretores das escolas públicas e sua relação com o bloco alfabetizador ${ }^{1}$
}

\section{The public schools principals and their relation to literacy block}

\author{
Los directores de las escuelas públicas y su relación con el \\ bloque de alfabetización
}

\section{Leonete Luzia Schmidt² \\ Rosinete Costa Fernandes Cardoso ${ }^{3}$}

\section{Resumo}

O presente artigo discute a atuação dos gestores escolares em relação ao Bloco Alfabetizador num contexto em que a alfabetização ganha destaque nas políticas educacionais, inclusive com determinação oficial de que os três primeiros anos do Ensino Fundamental sejam dedicados à alfabetização e ao letramento. Trata-se de um recorte da pesquisa realizada no âmbito do projeto Alfabetização com letramento: a formação inicial e continuada e trabalho docente nas escolas da rede pública da região sul de Santa Catarina, financiado pela Capes/Observatório da Educação. Os dados foram coletados através de entrevistas e de análise documental. Foram sujeitos da pesquisa os diretores de seis escolas pertencentes às redes estadual e municipal da região da AMUREL/SC. Os resultados evidenciaram que o modelo de gestão, que articula profissionais e recursos no interior da escola, mescla aspectos da gestão nas perspectivas democrática e gerencial. Isto condiciona uma dinâmica onde o engajamento na organização do trabalho pedagógico junto ao Bloco Alfabetizador fica à mercê do preparo e interesse individual de cada gestor.

Palavras-chave: Gestão escolar; Bloco Alfabetizador; Alfabetização.

1 Agência financiadora: CAPES/OBEDUC.

2 Doutora em educação e professora do Programa de Pós-graduação em Educação da Universidade do Sul de Santa Catarina. E-mail: leonetes@gmail.com

3 Mestre em educação e professora do curso de Pedagogia na Universidade do Sul de Santa Catarina e administradora escolar na EEB Gov. Aderbal Ramos da Silva, município de Tubarão. E-mail: rosinetecardoso@hotmail.com. 


\begin{abstract}
This present article discusses the role of school principal in relation to the Literacy Block in a context in which literacy is highlighted in educational policies, including official determination that the first three years of elementary school are dedicated to literacy and literacy. It's a part of a research carried out under the Literacy with literacy project: the initial and continuing education and teaching work in public schools of the south region of Santa Catarina, funded by Capes/Education Observatory. Data were collected through interviews and documentary analysis. Principals of six schools belonging to state and local network of AMUREL/SC region were research subjects. The results showed that the management model, that articulates professionals and resources within the school, gets the democratic aspects of the management and managerial perspectives. This conditions a dynamic where the engagement in the organization of educational work with the Literacy Block is at the mercy of the preparation and individual interest of each principal.
\end{abstract}

Keywords: School management; Literacy Block; Literacy.

\title{
Resumen
}

En este artículo se analiza el papel de los directores de escuela en relación al bloque de alfabetización en un contexto en el que la alfabetización se pone de relieve en las políticas educativas, incluida la determinación oficial de que los tres primeros años de la escuela primaria se dedican a la alfabetización. Esto es parte de una investigación llevada a cabo en el marco del proyecto de alfabetización: la educación y la enseñanza inicial y continuada en las escuelas públicas de la región meridional de Santa Catarina, financiado por la CAPES/ Observatorio de Educación. Los datos fueron recolectados a través de entrevistas y análisis de documentos. Los sujetos fueron los directores de seis escuelas pertenecientes a las redes estatales y municipales de la región Amurel/SC. Los resultados mostraron que el modelo de gestión, la combinación de profesionales y recursos dentro de la escuela combina aspectos de la gestión en las perspectivas democráticas y de gestión. Esto implica una dinámica en la que la participación en la organización del trabajo pedagógico con el bloque de alfabetización está a merced de la preparación y el interés individual de cada director.

Palabras-clave: Gestión escolar; Boque alfabetizador; Alfabetismo.

\section{Introdução}

[...] implantam esses sistemas [...] e a escola só corre pra [sic] tentar se adaptar, pelo menos nas exigências do sistema, mas não nas exigências do educando [...] que é o principal. (Mere) ${ }^{4}$

A princípio, a fala da gestora citada acima pareceu representar a realidade das escolas públicas que, oprimidas por um Estado autoritário, menosprezam as necessidades da criança. Mas o esforço por desvelar outras determinações que moldavam este universo, especialmente o que dizia respeito à atuação dos gestores em relação aos três anos iniciais do Ensino Fundamental, pôs em evidência mais que a reprodução das condições vivenciadas. De um lado, destacam-se práticas que reproduzem as condições para que a escola perpetue sua função mediadora no sistema capitalista, preparando uma parcela que pode ser absorvida na

4 Gestora da Escola A - trecho da fala retirada da entrevista realizada em 19/12/2011. 
produção (deixando à beira do caminho tantos outros), enquanto simboliza o caminho para a inclusão social de todos. E de outro, constatam-se indícios de negação do referido consenso, onde, a despeito da falta de condições, burlam as dificuldades, promovendo situações onde residem possibilidades de aprendizagem para todos e denúncias que refutam as condições reais de realizar as promessas que são creditadas à escola.

Mas, por que a escolha dessa fala? Que outras determinações apontam a declaração da gestora? Ela é emblemática, manifesta a falta de autonomia da escola; ressalta a resignação diante dessa situação; revela o foco na criança e não no conhecimento, matéria-prima do trabalho escolar, demandando, então, uma forma de lidar com o processo de ensino e aprendizagem que condiciona alguns resultados; e indica a percepção de desajuste, da direção "torta", o que pode se configurar como um indício de um querer fazer diferente, da necessidade de mudança.

A discussão a respeito da atuação dos gestores em relação ao Bloco Alfabetizador ${ }^{5}$ implica na reflexão sobre como foi se constituindo o contexto onde atuam esses profissionais, que, ao mesmo tempo, manifesta os condicionantes econômico-sociais da organização e gestão da escola e representa o espaço de resistência ao consenso que camufla o desinteresse pela universalização da aprendizagem da leitura e da escrita. O contexto aqui referido constitui-se na gestão escolar, que abriga os determinantes sociais que se enredam na atuação desses profissionais e na implantação do Ensino Fundamental de nove anos, com o enfoque dado ao Bloco Alfabetizador.

O modo como os profissionais se organizam na escola tem íntima relação com o modelo de gestão que impera na sociedade e, sendo a sociedade capitalista, a gestão da escola carrega marcas desse modelo inerente ao modo de produção capitalista.

Paro (1986) afirma que a administração entendida em seu sentido geral, abstraindo-se seus determinantes históricos, refere-se à "utilização racional de recursos para a realização de fins determinados" (PARO, 1986, p. 18). Contudo, a existência concreta da administração está sempre vinculada a determinantes sociais que, no âmbito do capitalismo, condicionam um conjunto de relações de produção que organiza os homens através de classes antagônicas. "A atividade administrativa não se dá no vazio, mas em condições históricas determinadas para atender a necessidades e interesses de pessoas e grupos” (PARO, 1986, p. 13).

As relações no sistema capitalista de produção expressam variadas formas de extorsão, incluindo desde as mais antigas até as mais sofisticadas formas de exploração empregadas para controlar a realização do trabalho e assegurar a manutenção desse sistema. Considerada uma estratégia de peso para a produção capitalista, a educação contribui com uma força de trabalho desigual, reproduzindo níveis diferenciados de aprendizagem, atuando, ainda, em outra frente, disseminando, enquanto instituição mediadora do sistema, a suposta igualdade de oportunidades educacionais presente nas diretrizes oficiais. À administração da escola, por sua vez, cabe organizar e gerir a instituição de modo que se constitua em elemento mediador, persuadindo e dissimulando os elementos da realidade concreta para ocultar as contradições da sociedade de classes. Todavia, essas mesmas contradições podem provocar abalos nas forças que condicionam a administração da escola, criando possibilidades de mudanças.

Segundo Paro (1986), a administração educacional ancorou-se nos modelos empresariais do século XX. Entretanto, o mesmo explica que o emprego da administração empresarial na escola se deu mais no sentido da utilização da perspectiva gerencial para propiciar o controle do trabalhador e muito menos para que fosse explorada sua dimensão técnica na busca por melhores resultados. Ou seja, desse modelo de gestão, o que foi absorvido na escola foram as estratégias para dirigir os profissionais e não necessariamente para melhorar os resultados, como se pretende na empresa capitalista. No entanto, ainda que seja óbvio, parece importante destacar que, ao controlar os profissionais, também são operados condicionamentos em favor de determinados resultados.

5 A expressão Bloco Alfabetizador refere-se aos três primeiros anos do Ensino Fundamental, definido no Parecer $n^{0}$ 4/2008, como um bloco pedagógico ou ciclo sequencial de ensino dedicado à alfabetização e ao letramento. 
O modelo de gestão capitalista, em vista de seus determinantes econômico-sociais, sofre transformações de modo que se conserve a dinâmica de sua existência e seja possível alcançar sua finalidade, que é o lucro. Neste trabalho, não se discute a trajetória do modelo de gestão capitalista da sua origem até a atualidade, dada a complexidade dessa questão, mas detém-se fundamentalmente, tendo em vista a influência indiscutível desse período na atualidade, nas reformas empreendidas a partir da década de 1990. Estas se configuram nas medidas tomadas em virtude da reestruturação sofrida pelo capital, que contribuiriam, inclusive, para a consolidação do termo gestão, em substituição à denominação administração.

Discutindo a década de 1980, Oliveira (2008) alega que, nesta década, constituiu-se no Brasil um rico período de conquistas democráticas, especialmente, para a educação pública, em que foram propostas "mudanças na gestão e na organização da educação e a valorização do magistério como profissão" (OLIVEIRA, 2008, p. 138). O clima de abertura política dessa época conflui para a gestão democrática da educação como a alternativa para que o planejamento e a administração da escola se realizassem a partir da participação coletiva, indicando maiores possibilidades de autonomia e autorregularão que desenham novas formas para a gestão escolar. A rotina administrativa da escola se alterou em função das medidas descentralizadoras. Para a autora, muito embora essa autonomia tenha se limitado à questão administrativa, financeira e pedagógica pelas administrações públicas, trouxe a oportunidade de mais participação na gestão da escola, variando em cada rede de ensino. Conforme a autora, foram essas mudanças que se refletiram na prática cotidiana das escolas, a ponto de contribuir para o aparecimento do termo "gestão educacional" à medida que se arrefecia o termo administração escolar, em virtude do entendimento de pesquisadores de que o vocábulo gestão superaria a conotação técnica da administração escolar e ampliaria a discussão, introduzindo a dimensão política.

Parece que a adoção do termo gestão incorpora o esforço por convencer de que se está vivenciando novos tempos na escola, que reforçam a gestão democrática e a autonomia como mecanismos para o envolvimento do coletivo e como uma resposta às necessidades de profissionais, alunos e familiares, questões estas das quais a administração não dava conta. A mudança, então, visa a representar uma alteração conceitual que só encontra correlação na rotina da escola se for considerado que a gestão democrática e a autonomia têm servido, na verdade, à descentralização imputada pelo Estado para desobrigar-se de suas responsabilidades com a educação. Vale ressaltar que, a despeito da reconfiguração perniciosa em torno da gestão democrática, entende-se que não há outro caminho, pois é pela via do coletivo cônscio e comprometido que as mudanças poderão se viabilizar. Entretanto, a gestão democrática aqui defendida é aquela que corresponde ao que Cury (2007, p. 494) define como

[...] transparência e impessoalidade, autonomia e participação, liderança e trabalho coletivo, representatividade e competência. Voltada para um processo de decisão baseado na participação e deliberação pública, a gestão democrática expressa um anseio de crescimentos dos indivíduos como cidadãos e do crescimento da sociedade enquanto sociedade democrática.

Essa gestão democrática não coaduna com o modelo de acumulação do capital que transfere parte do ônus da produção para o trabalhador, dissimulando esta responsabilização em novas formas de organizar a força de trabalho, mais autônomas e participativas, em momentos da produção em que tais aspectos melhorariam os resultados.

A centralização na Educação Básica, propagada pelos organismos internacionais no âmbito das reformas da década de 1990, desvela contornos encobertos quando cotejada com as transformações no sistema de acumulação capitalista, engendradas de modo a manter-se hegemônico. Todavia, a focalização da Educação Básica traz em seu bojo a contradição, pois pode constituir-se em chance para o acesso ao conhecimento.

Segundo Aguiar (2010), na década de 1990, a educação passa a ser novamente concebida como fator de equalização social e distribuição de renda. Desse modo, dá-se, no Brasil, a partir de prescrições dos organismos 
internacionais, reformas educacionais que direcionam as políticas e reconfiguram o sistema educacional, destacando-se, dentre estas, os programas de gestão (Qualidade Total na Educação; Pró-Gestão).

Assim, na década de 1990, a intensa relação entre a educação e os elementos estruturantes da dinâmica capitalista passa a delinear novas funções para a primeira. As mudanças que se operam vão acentuando seus contornos e disseminando novas interpretações para a administração da educação com impactos também no contexto da implantação do Ensino Fundamental de nove anos, em 2006, em especial ao aprendizado da leitura e da escrita nos três anos iniciais dessa etapa da escolaridade obrigatória.

Nos documentos constituídos pelo Estado - sejam as legislações ou os materiais do Ministério da Educação (MEC) que orientam a implementação do currículo de nove anos -, há evidências de uma preocupação em atenuar o baixo índice de alfabetização e letramento dos alunos no país. Tais documentos propõem uma nova organização administrativa e pedagógica para essa etapa do ensino, com notável prioridade para a fase da alfabetização dos alunos.

Considerando esse cenário, surgem vários questionamentos, dentre eles: como atuam os gestores das escolas frente a esta nova organização administrativa e pedagógica proposta oficialmente para o Bloco Alfabetizador? Entendendo que o Bloco Alfabetizador representa uma política pública de educação que interfere nas práticas do interior das escolas, de que modo os diretores incorporaram tais políticas? Que entendimento sobre o Bloco Alfabetizador tem subsidiado as práticas dos gestores das escolas?

O objetivo deste texto é conhecer a atuação dos gestores das escolas públicas da região sul de Santa Catarina em relação ao Bloco Alfabetizador nesse contexto em que a alfabetização ganha destaque nas políticas educacionais.

A pesquisa foi realizada em seis escolas públicas da região sul de Santa Catarina, definidas segundo critérios que assegurassem representatividade da região. Das seis escolas, quatro pertencem a redes municipais e duas à rede estadual de Santa Catarina. Em ambas as redes os diretores são nomeadores pelo chefe do Poder Executivo municipal e estadual, respectivamente. Desse total de diretores, cinco são mulheres e um homem, confirmando os dados em relação ao gênero, demonstrados por Souza (2009), em sua pesquisa sobre o perfil dos diretores das escolas no Brasil, que indica que a maioria dos que ocupam essa função é mulher Desses seis diretores, cinco são professores da rede de ensino e um deles é Técnico em Educação. Todos são formados em cursos de licenciatura, sendo três graduados em História e três, em Pedagogia.

A coleta de dados foi realizada nos anos de 2011 e 2012, período da vigência da pesquisa do Observatório da Educação (OBEDUC), tendo como principal instrumento a entrevista, complementada com análise documental. As entrevistas foram realizadas nas escolas em horários pré-agendados, gravadas e, posteriormente, transcritas. O Projeto Político Pedagógico das escolas foi o principal documento analisado.

A atuação dos gestores, assim como a dos demais profissionais da escola, é mediada pelo contexto sociocultural em que esta instituição está inserida e pelos processos de organização e gestão da Educação Básica que representam as políticas públicas voltadas a este nível de educação. Assim, analisar a atuação dos gestores das escolas públicas da região sul de Santa Catarina no contexto em que a alfabetização ganha destaque nas políticas educacionais implicou apreendê-la no âmbito das relações sociais em que se forjam as condições para sua proposição e materialidade.

Esse entendimento balizou a organização do presente texto cuja discussão está centrada em torno de dois pontos: gestão escolar nas políticas educacionais das últimas décadas e atuação dos gestores escolares no contexto dessas políticas em relação ao Bloco Alfabetizador.

6 No artigo "Perfil da gestão da escola pública no Brasil: um estudo sobre os diretores escolares e sobre aspectos da gestão democrática", Souza (2009) se propõe a elaborar um perfil da gestão da escola pública brasileira a partir da análise dos dados do Sistema de Avaliação da Educação Básica (SAEB) de 2003, concluindo, dentre outras questões, que 78\% dos dirigentes das escolas públicas brasileiras são mulheres (SOUZA, 2009, p. 2). 


\section{A gestão da escola a partir da década de 1990}

A sociedade contemporânea presenciou, nas últimas décadas, fortes transformações de natureza política, econômica e social. O processo de globalização e o modelo societário neoliberal ensejam políticas públicas e práticas voltadas para a construção de uma nova ordem social e política, advindas de uma nova ordem econômica em implantação desde a extensa e profunda "crise" sofrida pelas economias capitalistas nos anos de 1970.

A década de 1990 marca a emergência de uma nova conjuntura mundial, dada a necessidade visceral do sistema capitalista de realinhar suas estruturas tendo em vista que a crise em seu modelo de produção anuncia, com todas as consequências daí advindas, a crise de um determinado "modo de vida", a quebra de um pacto social, caracterizado pela busca do "pleno emprego", por certa estabilidade no trabalho e por amplas garantias sociais. No plano político, essa crise levou à derrocada dos governos e partidos socialdemocratas bem como da ideologia na qual se apoiavam. No plano microeconômico, ela se evidencia pelo lento crescimento ou mesmo queda da produtividade do trabalho. E, no plano macroeconômico, ocorre uma disputa na distribuição de lucros/salários que, tendendo a se agravar, implicou a elevação da inflação, uma vez que o capital, já não mais aceitando a elevação do salário real, começou a repassar aos preços dos produtos todo aumento de custo daí derivado.

A crise do fordismo originou-se e desenvolveu-se tanto por razões internas quanto externas a cada país, tanto no nível microeconômico quanto no macro, tanto na esfera produtiva quanto na órbita comercial e financeira das economias. A queda dos níveis de investimento, da atividade produtiva e do emprego, a crise fiscal do Estado (isto é, a crise de financiamento) e a aceleração da inflação se entrelaçaram, expressando as várias dimensões do problema.

Para Araújo e Castro (2011), as estratégias de responsabilização, empoderamento e descentralização da nova gestão pública trazem a distribuição de tarefas e delegação de poder decisório aos níveis inferiores da organização, também, incorporados pela escola: "Nessa acepção, as pessoas passam a ser responsáveis diretamente por suas decisões, no interior da escola, pelo seu sucesso ou pelo seu fracasso" (2011, p. 92). Os autores, ainda, alertam que a transferência de responsabilidades não contou com aportes financeiros e apoio técnico administrativo e pedagógico que possibilitassem escolas autônomas e efetivas, ao contrário, no lugar de mobilizar os atores para a redistribuição do poder, numa gestão democrática, o modelo secundariza a participação efetiva:

Nessa lógica, as estratégias de empoderamento que acontecem na escola, como exemplo, os Grêmios Estudantis, os Conselhos de Classe, os Conselhos Escolares, as Assembleias Gerais, as eleições para diretores e o planejamento estratégico servem muito mais para legitimar as ações voltadas para implementação da cultura organizacional gerencialista do que para fazer com que as pessoas possam participar, democraticamente, com poderes de decisão sobre os rumos da escola (ARAÚJO; CASTR0, 2011, p. 93).

Nesse cenário, as relações capitalistas em âmbito internacional e nacional produziram a transição da noção de prioridade da Educação Básica na década de 1980 à "centralidade da Educação Básica" na década de 1990, ambas articuladas à necessidade de readequação ideológica para mediar as mudanças econômicosociais necessárias ao processo de acumulação do capital e, ao mesmo tempo, para administrar a miséria social que elas produzem. Nesse sentido, a bandeira da Educação Básica, já no início da década de 1980 e na década de 1990, está vinculada às transformações que são efetivadas no âmbito da economia e da política em nível nacional e internacional.

Sobretudo na virada dos anos 1990, o debate mundial e nacional em torno da questão da "educação como fator de desenvolvimento" intensifica-se em face das exigências de um padrão de qualificação emergente no contexto de reestruturação produtiva e de globalização na economia. As discussões apresentam a necessidade de serem repensadas propostas e alternativas para problemas estruturais da educação, passando, necessariamente, por reformas nos sistemas públicos de ensino. 
Dessa forma,

essas transformações colocam em evidência a dinâmica própria do processo de reestruturação capitalista. São novos procedimentos adotados pela economia mundial, obrigando os estados nacionais a assumirem uma outra conduta política, que muitas vezes implica em aceitar a interferência de instituições externas, nem sempre formalizadas (OLIVEIRA, 2000, p. 26).

Frigotto e Ciavatta (2003) assinalam que os protagonistas dessas reformas, dentre os quais o Fundo Monetário Internacional (FMI), Banco Mundial (BIRD), Banco Interamericano de Desenvolvimento (BID) e o Programa das Nações Unidas para o Desenvolvimento (PNUD) são os responsáveis por encaminhar as reformas nos Estados, sobretudo nos países da periferia do capitalismo.

Indicando uma reedição da teoria do capital humano ${ }^{7}$, tão em voga nos anos de 1970, a educação passa a ocupar, nos anos de 1990, lugar central na reestruturação capitalista, sendo considerada crucial para enfrentar a competitividade acirrada, melhorar a produção e adquirir a tão propalada empregabilidade. Para Shiroma (2000), o ideário adjacente à política educacional da década de 1990 foi disseminado em nível global por publicações e eventos importantes patrocinados por agências como o Banco Mundial, Organização das Nações Unidas para a Educação, a Ciência e a Cultura (UNESCO), PNUD e Fundo das Nações Unidas para a Infância (UNICEF).

Os diagnósticos, análises e propostas de soluções constantes nas publicações, tanto para a educação quanto para a economia, prestavam-se a todos os países da América Latina e Caribe, e influenciaram as políticas públicas para a educação (SHIROMA; MORAES; EVANGELISTA, 2002).

A Conferência Mundial sobre a Educação para Todos em Jomtien, na Tailândia, no ano de 1990, considerada o grande marco das reformas que a seguiram, foi organizada pela UNESCO, UNICEF, PNUD e Banco Mundial. Subscrita por 155 governos que assumiram o compromisso de assegurar uma educação básica de qualidade a crianças, jovens e adultos, resultou em consensos que deveriam penetrar a formulação dos planos decenais de educação, em especial nos países mais populosos e com os maiores índices de analfabetismo do mundo (SHIROMA; MORAES; EVANGELISTA, 2002; OLIVEIRA, 2000).

Para Oliveira (2000), as reformas educacionais deflagradas nesse período pretenderam preparar a população para que se integrasse à sociedade atual e, mais recentemente, para a empregabilidade, um novo conceito que associa a Educação Básica à possibilidade de ingresso no mercado de trabalho.

Com a centralidade que a educação passa a ocupar nos discursos e práticas governamentais, sob orientação dos organismos internacionais, e, por decorrência, com a prioridade atribuída à Educação Básica oferecida pela escola regular, observa-se uma maior atenção às exigências de níveis de escolaridade dos trabalhadores para ingressarem e permanecerem no emprego formal.

Nesse contexto, novas características são atribuídas à gestão e organização do trabalho, assim como o perfil da força de trabalho. Essas alterações exigem trabalhadores mais polivalentes ou plurifuncionais, justificadas como uma consequência da flexibilização que aparece com o fim da produção estandartizada [fordista]. É nesse sentido que as novas exigências de qualificação vêm recaindo sobre a formação geral, capaz de proporcionar uma sólida base de conhecimentos aos trabalhadores, que devem se adaptar às mudanças na velocidade que a concorrência capitalista impõe.

Por conseguinte, toda política educacional, ao constituir-se em uma ação deliberada do Estado, revela a expressão das relações sociais cujas raízes se localizam no mundo da produção. O Estado, ao expressar a relação social, capital e trabalho, demonstra também as diferentes relações de força existentes na sociedade.

No Brasil, a centralidade da educação escolar está presente nas políticas educacionais voltadas à "universalização do Ensino Fundamental", nos anos de 1990, e da Educação Básica, nos anos de 2000;

7 Theodoro W. Schultz (1902-1998) foi o principal expoente da Teoria do Capital Humano (TCH), nos anos 50, nos Estados Unidos. Para este, a produção e, consequentemente, os lucros poderiam ser aumentados mediante o trabalho humano qualificado pela educação, pois compreende que o Capital Humano é "a soma dos investimentos do indivíduo em aquisição de conhecimentos e que a qualquer momento reverte em benefícios econômicos para o próprio indivíduo" (AGUIAR, 2012, p. 12). 
nas alterações no modelo de gestão escolar à semelhança do modelo de administração empresarial; na instituição de programas de qualidade e produtividade na gestão, dentre outras políticas educacionais e ações governamentais voltadas à educação.

De acordo com Rosar (1999), na década de 1980 amplia-se o debate em torno das perspectivas conservadora e progressista na administração educacional, resultando na discussão da democratização da educação e sua gestão democrática entre as entidades que compunham o Fórum Nacional de Defesa da Escola Pública mesmo depois do Congresso Constituinte. A autora lembra, ainda, que paralelamente a esse movimento, outro, de contornos ainda maiores, acontecia.

Na realidade, enquanto se elaboravam, do ponto de vista dos setores progressistas na área da educação, as concepções que seriam consagradas nos anteprojetos de LDB pela sua participação efetiva no debate nas Comissões da Câmara e do Senado, estava sendo formulada a política do Banco Mundial para América Latina, neste final de século, sob a ótica do modelo 'democrático atualizado', segundo a perspectiva hegemônica do neoliberalismo no campo econômico e político (p. 167, grifo da autora).

Com relação à gestão da educação, foi proposta nas reformas a modernização da gestão pública nos moldes da gestão privada, criando a chamada administração pública gerencial, centrada na eficiência, na qualidade, na descentralização, nos resultados alcançados pelos serviços públicos e em uma cultura gerencial das organizações.

Segundo Shiroma (2006, p. 2):

0 ideário da gestão, especialmente aquele difundido pelos organismos internacionais e assimilado pelos governos locais, parece sustentar-se em duas ideias básicas: a) a gestão eficaz está na base da qualidade dos sistemas e das unidades escolares e, b) para que se obtenha essa eficácia, é necessário profissionalizar as atividades, em especial, os docentes e gestores.

Essa autora enfatiza que "as repercussões desse movimento podem ser observadas na renomeação dos cargos de direção, no setor público, pelo termo de 'gerente'” (2006, p. 5, grifo da autora). E que o gerencialismo é apresentado como estratégia racional para fazer o melhor uso dos recursos públicos. "Busca aumentar a produtividade e a eficiência e toma como indicador de desempenho os resultados" (SHIROMA, 2006, p. 5). Para ela a gestão por resultados é compatível com a autonomia da equipe sobre o processo, pois se trata de uma autonomia regulada, controlada pela avaliação que incide sobre o produto.

Nessa conjuntura, paira sobre o diretor a expectativa de que, fundamentado nos princípios da gestão democrática, deve manter a escola funcionando, estabelecer o diálogo com a comunidade e favorecer o trabalho coletivo. Entretanto, as condições de trabalho a que estão submetidos os profissionais da educação - de carência material, aumento da carga horária e obrigações - dificultam a participação efetiva e politizada destes na escola. Conforme Oliveira (2008, p. 143), "pesa sobre os ombros do diretor uma intensificação do trabalho, já que se encontra impedido de delegar poder e dar ordens, em razão de que a noção de subalternidade foi substituída por uma retórica que valoriza o trabalho coletivo e as relações horizontais".

Nessa perspectiva, a ampliação do Ensino Fundamental em um ano, passando de oito para nove anos, e a inclusão desse um ano a mais na etapa da alfabetização representa mais uma atribuição à função do diretor, pois este, equipe gestora e professores precisariam implementar essa política, tendo em vista a necessidade de melhorar os índices de alfabetização, que, segundo dados do Censo 2010, revelam que 15\% das crianças não estão alfabetizadas aos oito anos (BRASIL, 2010).

\section{A atuação dos diretores no contexto do Bloco Alfabetizador}

Em Santa Catarina, na rede estadual de ensino e na maioria das redes municipais o processo e implantação do currículo do Ensino Fundamental de nove anos iniciou após a aprovação a Lei n 11.274/06. Em algumas redes municipais esse processo teve início em 2005. Mas, independente do momento da implementação dessa nova estrutura, muitos eram os desafios a serem vencidos, desde a compreensão da proposta pelos profissionais 
da escola até a reorganização da estrutura física e de mobílias. A promulgação da Lei n 11.274/06 parece que causou nos profissionais da educação que atuam na escola certo estranhamento diante da entrada da criança aos seis anos no Ensino Fundamental, evidenciado em manifestações de contrariedade e/ou insegurança.

Nas respostas dadas pelos diretores das escolas às perguntas feitas durante a entrevista tem-se a impressão que estes possuem uma compreensão vaga das políticas educacionais a partir das quais as mudanças no Ensino Fundamental vinham sendo geridas e um certo afastamento dos desdobramentos que ocorrem na escola a partir destas. Quando questionados sobre as mudanças ocorridas na proposta pedagógica em virtude do Ensino Fundamental de nove anos, os diretores, em sua maioria, mais se preocupam em mostrar o que consideram as consequências dessa mudança (a entrada da criança aos seis anos; a necessidade de adequação do currículo; o despreparo, especialmente do professor, mas também das crianças e da escola como um todo), pouco esclarecendo sobre as possíveis alterações ou ações no fazer da escola.

Constata-se que os diretores perceberam a alteração da rotina da escola com a entrada das crianças de seis anos no Ensino Fundamental. Apontam que a escola precisa lidar com situações que não se registravam de forma tão evidente, como a necessidade das crianças do brincar, de não ficar sentado. Demonstram isso as falas das diretoras das Escolas 01, 02 e 03. A primeira diz que "tá [sic] sendo muito cedo para a criança entrar na escola. Onde tira, por exemplo, o espaço dela, a liberdade dela brincar. Que ela está no $1^{\circ}$ ano, então, assim, ela não tinha aquele compromisso de querer ficar sentada de [...], né [sic], querer escrever". A segunda afirma: "Ficou mais difícil de trabalhar, [...] enquanto ela deveria tá [sic] lá na Pré-escola, ela tá [sic] aqui [...] ela tá [sic] perdida naquele mundo, que ali não é o mundo, não é a hora, não é o mundo dela aquilo ali, que ela devia tá [sic] lá na Pré-escola. [...] tem exemplos de criança que quer [sic] brincar, ela tá [sic] ali na escola [...]." A terceira diz que "[...] de repente tirou o aluno do [...] da parte lúdica, tirou a fantasia do aluno, muito eu vi isto nas escolas, né [sic]. Muito eu vi essa parte assim acontecendo [...] que tirou aquela [...] a parte lúdica, a fantasia do aluno e trouxe ele [sic] para uma carteira e disse: 'aqui tu vai [sic] estudar e vai ter que ser assim, tu vai [sic] aprender e pronto'." Da mesma forma, a diretora da escola 04 ressalta a questão relacionada à adaptação da criança de seis anos no Ensino Fundamental. Ela relata que: "[...] no nosso primeiro bimestre aqui a gente tá [sic] percebendo que realmente o aluno [...] ainda temos alunos que não aceitam estar aqui." Mesmo percebendo que a escola não atende às necessidades de aprendizagem e desenvolvimento da criança, estes profissionais não evidenciam manifestações que indiquem uma reação às medidas exigidas à escola. A gestão democrática anunciada parece se resumir em acatar as determinações oriundas das secretarias, mesmo que a escola não tenha participado das decisões ou tenha condições para sua implementação.

A prática do professor alfabetizador também é indicada como um dos problemas enfrentados nesse processo de mudança. Conforme a diretora da escola 05, as professoras não estavam preparadas para o ingresso da criança de seis anos no Ensino Fundamental, pois persiste nestas a preocupação em dar conta do conteúdo. Para ela, as professoras não conseguem se desvencilhar do modelo anterior de currículo, onde a alfabetização deveria acontecer no primeiro ano. "[...] então eu vejo assim, ó, [sic] que por mais que a prefeitura, por mais que o MEC, não sei [...], eles tentem passar o [...] né [sic], um currículo diferente, o professor ainda não tá [sic]." (Fala da diretora da escola 05). Já a diretora da escola 03, alega que "toda lei, né [sic], foi bem aceita, mas eu acho que faltou uma preparação aí para todos: alunos, professores, escola." Esta declarou, ainda, a preocupação com rotatividade de professores e a falta de continuidade dos trabalhos no Bloco Alfabetizador. O diretor da escola 06 acredita que ocorreram mudanças, diz que a Gerência Regional de Educação deu cursos sobre o tema para ajudar os professores a organizarem esse Bloco Alfabetizador, sem esclarecer sobre as possíveis mudanças na escola.

De uma forma geral, os diretores verificam que houve alteração na organização e funcionamento da escola, principalmente quanto à maturidade das crianças para estar no Ensino Fundamental; necessidade de brincar manifestada pelas crianças e despreparo do professor para alfabetizar na perspectiva do Bloco alfabetizador. 
No entanto, não ficou claro se houve reflexões sobre os aspectos apontados que levassem a constatar até que ponto estes têm relação com a gestão no interior da escola e com a atuação do diretor.

Oliveira (2000) observa que a sobrecarga de tarefas administrativas sem o suporte necessário pode acarretar na ausência de uma intervenção mais sistemática do diretor nas questões que dizem respeito às funções da escola. Segundo ela, "[...] as tarefas administrativas vêm absorvendo quase todo o tempo do diretor, esvaziando de conteúdo crítico e analítico suas atitudes, reduzindo-o à função de gerente, de controlador da força de trabalho e de administrador de recursos escassos" (OLIVEIRA, 2000, p. 253).

Discutindo sobre a defesa que os neoliberais fazem dos pressupostos gerencialistas para a gestão da escola, a autora ressalta que a esta tem sido atribuída até as condições de possibilitar a gestão democrática, haja vista que suas técnicas poderiam resolver os problemas enfrentados no cotidiano escolar, desde que assimilada e introjetada a "competência" da economia privada na gestão da escola pública (OLIVEIRA, 2000, p. 256).

Acontece que, para o diretor, despender de competência técnica empresarial como forma de enfrentamento das demandas advindas com a descentralização administrativa, sem contar com as condições materiais e com a autoridade que a função já possuiu, é experimentar a precarização de seu trabalho e aceitar o convite para que se afaste a dimensão pedagógica de sua função.

O afastamento das questões pedagógicas nas atribuições dos diretores, principalmente das relacionadas ao Bloco Alfabetizador, parece ser a realidade nas escolas da região sul de Santa Catarina.

Quando indagados sobre o planejamento na escola para o Bloco Alfabetizador, percebe-se que os diretores não têm muita clareza sobre como e quando é realizado. Demonstram que esta é uma atividade desenvolvida pelos professores que é, ocasionalmente, acompanhada pelo diretor e/ou outro profissional que atua na gestão pedagógica da escola. Alguns diretores logo se reportavam ao planejamento conhecido como planejamento anual, planejamento de curso. Os momentos empregados na escola para esse tipo de planejamento concentramse, em sua maioria, no início do ano letivo, salvo para duas delas que afirmaram rever essa atividade trimestral ou semestralmente. Quer dizer, o planejamento tem uma temporalidade organizada na gestão da escola. O diretor da escola 06 reforça a constatação de isolamento do professor no que tange ao momento do seu planejamento: "A gente, no geral, é que dá suporte, né? [sic]. Nós e a equipe num todo. Se um professor vem pedir auxílio, a gente até busca, vai atrás, mas normalmente elas trabalham entre elas, né?" [sic].

O que parece, à primeira vista, é um certo desinteresse pelo processo de planejamento e assessoria relativos ao professor do Bloco Alfabetizador, a exemplo de falas como: "Como é que eu respondo isso? [...] Tu quer [sic] saber como é feito este planejamento? Olha, esse, o planejamento, são os próprios professores, eles se reúnem toda semana, se reúnem para estar planejando [sic] a aula, tudo o que acontece durante a semana, aí eles, elas é que se reúnem para fazer este planejamento [...] se é isso que queres [...]" (Diretora da escola 02). "É semestral. É semestral. A cada semestre, conforme a determinação da GERED [...] até por espaço de tempo, né [sic] [...] que a gente não tem aquele espaço especial [...] a cada vez [...] uma vez por mês [...] ou coisa parecida [...]" (Diretor da escola 06). "Dependendo da necessidade do professor, sabe, assim, orienta, né [sic], eu mesma assim às vezes." (Diretora da escola 05). "Na verdade, é a nossa Assessora, juntamente com a orientação e supervisão" (Diretora da escola 04).

No entanto, esse distanciamento das ações pedagógicas pode, na verdade, indicar um sentimento de impotência que assola os diretores ante as dificuldades de toda ordem que têm de enfrentar: carência de recursos materiais, rotatividade de professores, dificuldades para estabelecer o diálogo com a comunidade local e articular o trabalho coletivo, necessidade de buscar parcerias para complementar o financiamento dos gastos na escola, formação que lhes dê condição para compreender o papel da escola e do diretor, seja numa perspectiva produtivista ou numa perspectiva democrática.

Paro (2006), ao discutir os condicionantes institucionais do autoritarismo que imperam a gestão democrática da escola pública, advoga que ao colocar o diretor como responsável último pela escola, que não recebe as 
mínimas condições de funcionamento, o Estado faz dele o primeiro a quem se culpará pela ineficiência da escola e pela tomada de decisão que nela se dá. Segundo ele, "por isso, uma real consciência crítica da situação por parte dos diretores deveria fazê-los rebelar-se contra essa migalha de poder, lutando por um efetivo poder para a escola, que seja aí distribuído entre todos os seus agentes e usuários" (PARO, 2006, p. 24, grifos do autor). Mas as falas dos diretores entrevistados não apontam nessa direção que Paro aborda sobre o diretor rebelarse e lutar por um efetivo poder para a escola. A prática que revelam existir na escola tem uma marca forte na desarticulação entre os sujeitos que ali atuam. Quanto à assessoria pedagógica ao Bloco Alfabetizador durante o processo de implantação dessa nova organização curricular na escola, as respostas revelam a fragmentação das atribuições entre a equipe da direção (gestores das escolas). Não se observa um projeto da e para a escola, foco para onde convergem as ações de todos a partir das suas especificidades.

A assessoria pedagógica dos diretores ao professor do Bloco Alfabetizador acontece em momentos pontuais: "No primeiro encontro no início do ano e na metade do ano, é discutido [sic] os temas, os planejamentos" (Diretora da escola 01); um trabalho onde o diretor aponta os responsáveis e reconhece sua importância para o Bloco Alfabetizador: "As meninas aqui, as supervisoras, as orientadoras, elas [sic] sempre dão o foco maior, tá [sic], porque é onde a gente tem um problema maior [...]" (Diretora da escola 02); conforme as necessidades do professor: "[...] dependendo da necessidade do professor" (Diretora da escola 05); como algo que "até" pode ser com o diretor: "[...] sabe, assim, orienta, né [sic], eu mesma assim às vezes [...]" (Diretora da escola 05); carregado de descontinuidade: "[...] quem sabe as orientadoras vão pegar parte desse trabalho, né [sic], então, assim, ó [sic], a gente contava com o auxílio de uma professora a, [...] readaptada, de séries iniciais, que dava essa [...] esse suporte, né [sic], não 100\%, porque ela [...] ela [...] também cuidava da biblioteca" (Diretor da escola 06); como uma tarefa: "[...] Ela só, né [sic], ela só nos [...] nos informa o que que [sic] ela precisa e a gente prepara todo o trabalho para a professora. Se ela precisa, né [sic], em sala de aula, "preciso deste material', então é a forma que a gente tem de tá assessorando [sic]" (Diretora da escola 03); e como um trabalho que se delega: "[...] Na verdade, é a nossa Assessora, a [...], juntamente com a orientação e supervisão" (Diretora da escola 04).

Essa forma de atuação no assessoramento pedagógico, comprovada nas falas acima, vai na contramão da perspectiva democrática. Não pode ser classificado como assessoria pedagógica o que os diretores dizem ser realizado na escola. São momentos pontuais e desarticulados.

Veiga e Fonseca (2001, p. 49) asseguram que um dos pressupostos constitutivos do planejamento estratégico-empresarial refere-se à separação dos pensadores dos concretizadores. "Isso significa que os dirigentes da escola e os especialistas afastam-se das práticas e os professores desligam-se das decisões. Nesse caso, fortalecem-se o individualismo e o isolamento." A considerar os relatos dos diretores, essa parece ser a realidade das escolas da região sul de Santa Catarina.

\section{Considerações finais}

Considerando que a realidade não é algo cristalizado, isento de rupturas, as inferências acerca da atuação dos diretores das escolas públicas da região sul de Santa Catarina no contexto de políticas educacionais que focalizam a alfabetização devem ser tomadas como provisórias.

Pôde-se perceber que a ampliação do tempo destinado à alfabetização e o ingresso da criança aos seis anos de idade no Ensino Fundamental impactaram a rotina de trabalho dos diretores, visto que mencionam o despreparo do professor para atuar nas classes de alfabetização com crianças de seis anos, o fato dessas crianças só quererem brincar e de ter mais atividades lúdicas como problemáticas advindas dessa nova organização curricular. Ou seja, os seis diretores observaram mudanças na rotina do Ensino Fundamental por conta da instituição do Bloco Alfabetizador e seus desdobramentos de ordem administrativa e pedagógica. 
Contudo, a mudança não parece ter interferido expressivamente na atuação destes, pois, salvo algumas exceções, manifestam indícios da perspectiva gerencialista quando delegam para o professor e à criança, quer dizer, para quem realiza o trabalho, a responsabilidade pelos resultados. Não evocam a complexidade da questão, reduzindo-a aos fatores internos à escola, manifestando a dinâmica da descentralização, ou melhor, da responsabilização da escola por atribuições que deveriam ser do Estado. Dentre as causas para isso, está possivelmente, a forma como são implementadas as políticas direcionadas ao campo da educação, no mais das vezes, sem se orientar pela perspectiva democrática, excluindo os sujeitos de processos que poderiam levar ao desvelamento de fatores que condicionam as situações vividas. Entretanto, sugere-se que, quando esses profissionais denunciam as precárias condições de trabalho, manifeste-se aí a contradição pontuada por Rosar (1999, p. 172) - "o processo dialético entre a teoria e a prática da gestão democrática, enquanto permanecem as organizações educacionais e sociais administradas sob a égide do capitalismo" -, o que, conforme ela "permite que se evidencie dentro do mesmo contexto um movimento de avanço teórico e prático, embora as políticas governamentais tentem descaracterizar as concepções e as propostas mais avançadas para o desenvolvimento da educação básica" (ROSAR, 1999, p. 172).

O acompanhamento pontual e superficial que se verifica na dinâmica de planejamento e assessoria ao professor do Bloco Alfabetizador pode ser um indício da precarização do trabalho do diretor. Por outro lado, é possível deduzir que, incorporando a dinâmica da descentralização, os diretores remetem para o âmbito da escola a responsabilidade pelos resultados com a justificativa de que "o professor não está preparado" e "a criança é muito nova", excluindo fatores externos que interferem na prática pedagógica.

Todavia, há de se ressaltar que, embora sutis, as tentativas de enfrentar as dificuldades, ainda que por "meios tortos", como a assessoria na medida dos problemas e em correspondência às solicitações, ou mesmo no reconhecimento da necessidade do lúdico para a criança, parecem esboçar um movimento contrário, por parte da escola, em relação ao gerencialismo na gestão escolar e aos objetivos ocultos da centralidade na Educação Básica. Explicando, elas podem apontar nuances de resistência à função reprodutora e a mecanização das relações no interior da escola, tão queridas ao sistema capitalista.

\section{Referências Bibliográficas}

AGUIAR, Letícia Carneiro. Formação docente, política curricular e a reedição da teoria do capital humano

no Brasil. Cadernos de Pesquisa em Educação - PPGE/UFES. Vitória, ES. a. 9, v. 18, n. 36, p. 11-32, jul./dez. 2012 Um legado do século XX para a política educacional do século XXI: a teoria do capital humano. Revista HISTEDBR On-line, Campinas, n. 40, p. 126-144, dez. 2010. ISSN: 1676-258412612. Disponível em: <http://www.fae.unicamp.br/revista/index.php/histedbr/article/view/3374>. Acesso em: 8 abr. 2013.

ARAÚJO, Suêldes de; CASTRO, Alda Maria Duarte Araújo. Ensaio: Aval. Pol. Públ. Educ., Rio de Janeiro, v. 19, n. 70, p. 81-106, jan./mar. 2011. Disponível em: <http://www.scielo.br/pdf/ensaio/v19n70/v19n70a06.pdf>. Acesso em: 8 abr. 2013.

BRASIL. Censo 2010. Disponível em: <http://portal.mec.gov.br>. Acesso em: 21 fev. 2013.

CURY, Carlos Roberto Jamil. A gestão democrática na escola e o direito à educação. RBPAE, v. 23, n. 3 , p. 483-495, set./dez. 2007.

FRIGOTTO, Gaudêncio; CIAVATTA, Maria. Educação Básica no Brasil na Década de 1990: Subordinação Ativa

e Consentida à Lógica do Mercado. Revista Educação e Sociedade, Campinas, v. 24, n. 82, p. 1-360, abr. 2003.

OLIVEIRA, Dalila Andrade. Educação Básica: gestão do trabalho e da pobreza. Petrópolis, RJ: Vozes, 2000. Mudanças na organização e na gestão do trabalho na escola. In: OLIVEIRA, Dalila Andrade; ROSAR, Maria de Fátima Felix (Org.). Política e Gestão da Educação. 2. ed. Belo Horizonte: Autêntica, 2008. p. 127-145.

PARO, Vitor Henrique. Administração Escolar: introdução crítica. São Paulo: Cortez, 1986. 
Gestão democrática da escola pública. 3. ed., 10ª imp. São Paulo: Editora Ática, 2006.

ROSAR, Maria de Fatima Felix. A dialética entre a concepção e a prática da gestão democrática no âmbito da educação básica no Brasil. Educação \& Sociedade, ano XX, n. 69, dez. 1999.

SHIROMA, Eneida Oto. Educação Profissional e Profissionalização de Educadores. Revista Perspectiva, ISSN print 0102-5473, ISSN 2175-795X Florianópolis, Santa Catarina, Brasil. Capa, v. 18, n. 33, 2000. Disponível em: <http://www.periodicos.ufsc.br/index.php/perspectiva/article/view/9386/8638>. Acesso em: 18 mar. 2013.

Gerencialismo e Liderança: novos motes da gestão educacional. Mesa redonda apresentada no VI Seminário de Pesquisa em Educação na Região Sul - ANPEd Sul, Santa Maria, jun. 2006.

SHIROMA, Eneida Oto; MORAES, Maria Célia Marcondes de; EVANGELISTA, Olinda. Política Educacional. 2. ed. Rio de Janeiro: DP\&A, 2002.

SOUZA, Ângelo Ricardo de. Perfil da gestão da escola pública no Brasil: um estudo sobre os diretores escolares e sobre aspectos da gestão democrática. 2009. Disponível em: <http://www.anped.org.br/ reunioes/30ra/index.htm>. Acesso em: 18 mar. 2013.

VEIGA, IIma Passos Alencastro; FONSECA, Marília. (Org.). As dimensões do projeto político-pedagógico: novos desafios para a escola Campinas, SP: Papirus, 2001. 